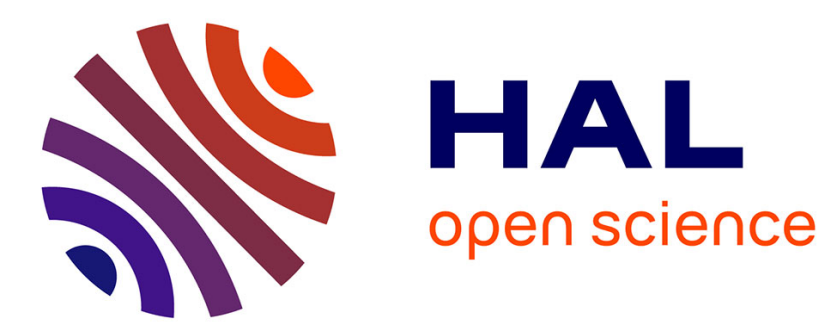

\title{
Some remarks on the review "Quantitative evaluation of the EBIC contrast of dislocations " by C. Donolato
}

L. Pasemann

\section{To cite this version:}

L. Pasemann. Some remarks on the review "Quantitative evaluation of the EBIC contrast of dislocations " by C. Donolato. Journal de Physique Lettres, 1984, 45 (3), pp.133-136. 10.1051/jphyslet:01984004503013300 . jpa-00232319

HAL Id: jpa-00232319

https://hal.science/jpa-00232319

Submitted on 1 Jan 1984

HAL is a multi-disciplinary open access archive for the deposit and dissemination of scientific research documents, whether they are published or not. The documents may come from teaching and research institutions in France or abroad, or from public or private research centers.
L'archive ouverte pluridisciplinaire HAL, est destinée au dépôt et à la diffusion de documents scientifiques de niveau recherche, publiés ou non, émanant des établissements d'enseignement et de recherche français ou étrangers, des laboratoires publics ou privés. 
Classification

Physics Abstracts

$07.80-73.40 \mathrm{~L}-61.70 \mathrm{~J}$

\title{
Some remarks on the review « Quantitative evaluation of the EBIC contrast of dislocations » by C. Donolato
}

\section{Pasemann}

Sektion Physik der Karl-Marx-Universität Leipzig, Arbeitsgemeinschaft $A_{3} B_{5}$-Halbleiter, 7010 Leipzig, Karl-Marx-Platz, Hauptgebäude, D.R.G.

(Reçu le 23 juin 1983, révisé le 14 novembre, accepté le 14 décembre 1983)

\begin{abstract}
Résumé. - La formulation donnée par divers auteurs, de l'efficacité de recombinaison d'une dislocation est discutée. On propose finalement une nouvelle expression qui est quasiment indépendante de la durée de vie des porteurs du matériau massif.
\end{abstract}

\begin{abstract}
Contrary views on an appropriate representation of the recombination strength of a dislocation are discussed with the consequence that a new fonction is proposed which describes the recombination strength nearly independent of the lifetime of the bulk.
\end{abstract}

This paper refers to the discussions by C. Donolato [1] of the EBIC contrast analysis proposed in [2] for the case of a straight dislocation parallel to both the surface and the junction of a semiconductor diode (Fig. 1B). In particular, his considerations on the recombination strength of a single dislocation give cause to re-examine the expression of the so-called real recombination strength introduced by [3].

First, some results already published on this subject are to be summarized. In the first-order approximation the image contrast of a dislocation can be written as $[1,4]$

$$
c\left(z_{0}\right)=\hat{\lambda}_{1} c^{*}\left(z_{0}\right),
$$

where $z_{0}$ denotes the dislocation-junction distance, and

$$
\lambda_{1}=\pi\left(r_{\mathrm{d}} / L\right)^{2}\left(\frac{\tau}{\tau^{\prime}}-1\right) \quad\left(\simeq \pi\left(\frac{r_{\mathrm{d}}}{L^{\prime}}\right)^{2} \text { if } \frac{\tau}{\tau^{\prime}} \gg 1\right)
$$

is the first-order recombination strength with $r_{\mathrm{d}}$ being the radius of the cylindrically assumed region of a dislocation. $\tau$ and $\tau^{\prime}$ are the lifetimes outside and inside the dislocation, respectively, and $L=\sqrt{D \tau}, L^{\prime}=\sqrt{D \tau^{\prime}}$ with $D$ being the diffusion coefficient. The function $c^{*}\left(z_{0}\right)$ takes into account the common effect of bulk recombination, surface, carrier generation, and dislocation position on the contrast. However, $c^{*}$ is independent of the parameters $r_{\mathrm{d}}$ and $\tau^{\prime}$ which characterize the recombination efficiency of a dislocation within the model. 


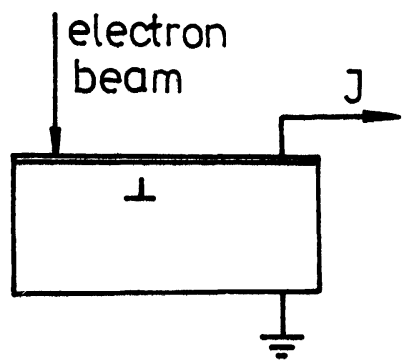

A

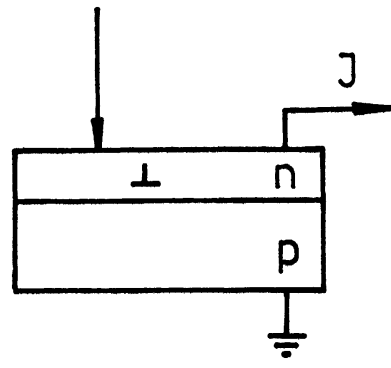

B

Fig. 1. - Schematic illustration of configurations used in EBIC observations of dislocations. (A) : Schottky barrier and (B) : p-n junction charge collection (after Donolato [1]).

Taking into account the contribution of the higher than first-order terms to the contrast according to [3] $\lambda_{1}$ in (1) has to be replaced by

$$
\begin{aligned}
\lambda & =\lambda_{1} /\left[1+\left(\lambda_{1} / 2 \pi\right)\left(\ln \left(2 L / r_{\mathrm{d}}\right)-C+\frac{1}{4}+\frac{1}{2} F\left(z_{0}\right)\right)\right] \\
& \simeq \lambda_{1} /\left[1+\left(\lambda_{1} / 2 \pi\right)\left(K_{0}\left(r_{\mathrm{d}} / L\right)+\frac{1}{4}+\frac{1}{2} F\left(z_{0}\right)\right)\right],
\end{aligned}
$$

where formula (3) is only valid on the assumptions $r_{\mathrm{d}} \ll L, z_{0}$. Here, $C=0.5772 \ldots$ is the Euler constant, and $K_{0}$ is the modified Bessel function of second kind of the zero order.

In (3) $F$ is independent of $r_{\mathrm{d}}$ and $\tau^{\prime}$, but dependent on the position of the dislocation. Therefore, the ratio $c / c^{*}$ is no longer an appropriate quantity to characterize the real recombination strength, as this is predicted by the first-order approximation [1]. Only in the case of weakly efficient dislocations, e.g. non-dissociated $60^{\circ}$ dislocations (cf. [2]), for which the ratio $c / c^{*}$ is approximately independent of the dislocation depth, it holds that $c / c^{*} \simeq \lambda_{1}$, and the first-order solution is a good approximation with $\lambda_{1}$ being an appropriate recombination strength.

According to Donolato [1] also in the case of strong efficient dislocations, e.g. dissociated $60^{\circ}$ dislocations (cf. [2]), for which the ratio $c / c^{*}=\lambda$ shows a strong dependence on the dislocation depth, $\lambda_{1}$ should be the characteristic measure for the recombination strength. This opinion seems incomprehensible to me, because in thisisase $\lambda_{1}$ does not describe completely the strength of a dislocation with respect to its EBIC contrast : according to (3) in addition to $\lambda_{1}$ the Bessel function $K_{0}$ is dependent on the radius $r_{\mathrm{d}}$, i.e. one of the two parameters which determine the recombination strength.

In order to separate completely the effect of the recombination strength of a dislocation to the EBIC contrast from the effect of both the surface and the dislocation position the function $\lambda(3)$ was rewritten as [3]

$$
\lambda=\lambda^{*} /\left[1+\left(\lambda^{*} / 4 \pi\right) F\left(z_{0}\right)\right]
$$


where

$$
\lambda^{*}=\lambda_{1} /\left[1+\left(\lambda_{1} / 2 \pi\right)\left(\ln \left(\frac{2 L}{r_{\mathrm{d}}}\right)-C+\frac{1}{4}\right)\right] \simeq \lambda_{1} /\left[1+\frac{\lambda_{1}}{2 \pi}\left(K_{0}\left(\frac{r_{\mathrm{d}}}{L}\right)+\frac{1}{4}\right)\right] .
$$

so that the contrast can be expressed by

$$
c\left(z_{0}\right)=\left[\frac{\lambda^{*}}{1+\left(\lambda^{*} / 4 \pi\right) F\left(z_{0}\right)}\right] c^{*}\left(z_{0}\right) .
$$

Now, in the representation (6) of the contrast only the function $\lambda^{*}$ involves the parameters $r_{\mathrm{d}}$ and $\tau^{\prime}$. Therefore, $\lambda^{*}$ should be more suitable to describe the recombination strength than $\lambda_{1}$. As the functions $c^{*}$ and $F$ are known [1-4] $\lambda^{*}$ can be determined if experimental values of the image contrast are available (cf. [2]).

Against the introduction of the function $\lambda^{*}$ for the recombination strength, a serious argument by Donolato [5] is the fact that $\lambda^{*}$ vanishes in the limit of vanishing bulk recombination $(L \rightarrow \infty)$. This is an incorrect behaviour, because the contrast function $c\left(z_{0}\right)$ does not vanish in the limit of long diffusion lengths, i.e. both the function $c^{*}\left(z_{0}\right)$ (cf. $\left.[2,4]\right)$ and the function $\lambda(3,4)$ does not go to zero. To illustrate the behaviour of $\lambda$ the function $F\left(z_{0}\right)$ given by [3] is now considered for two practically relevant examples. For the structure $\mathrm{A}$ of figure $1 F$ is given by

$$
F=-2 K_{0}\left(2 z_{0} / L\right) \rightarrow 2 \ln \left(z_{0} / L\right) \text { as } L \rightarrow \infty,
$$

and for the structure $B$, if the surface recombination velocity is sufficiently large (see [6]), one has

$$
\begin{aligned}
F= & -2 \sum_{n=0}^{\infty}\left[K_{0}\left(\frac{2 n d+2 z_{0}}{L}\right)+K_{0}\left(\frac{2 n d+2\left(d-z_{0}\right)}{L}\right)-\right. \\
& \left.-2 K_{0}\left(\frac{2(n+1) d}{L}\right)\right] \rightarrow 2 \ln \left(z_{0} / L\right) ; \quad L \rightarrow \infty .
\end{aligned}
$$

Consequently, in the limit of long diffusion lengths the logarithmic singularity of $F$ cancels out the logarithmic singularity which makes $\lambda^{*}$ zero, so that the function $\lambda$ given by (4) does not vanish.

Now, instead of $\lambda^{*}$ for the real recombination strength a new quantity is proposed which does not go to zero if $L \rightarrow \infty$ :

with

$$
\hat{\lambda}_{\mathrm{c}}^{*}=\hat{\lambda}_{1} /\left[1+\left(\hat{\lambda}_{1} / 2 \pi\right)\left(\ln \left(\mu \mathrm{m} / r_{\mathrm{d}}\right)+C^{*}\right)\right]
$$

$$
C^{*}=\ln 2-C+\frac{1}{4} \simeq 0.366 \text {. }
$$

This function has the property of being independent of the diffusion length $L$ of the bulk, if $\tau / \tau^{\prime} \gg 1$. Of course, the contrast function (6) can only be expressed by the correct recombination strength (7) if in addition to the substitution $\lambda_{\mathrm{c}}^{*}$ for $\lambda^{*}$ the function $F\left(z_{0}\right)$ is replaced by

$$
F_{\mathrm{c}}\left(z_{0}\right)=F\left(z_{0}\right)+\ln (L / \mu m)
$$

so that the contrast is given by

$$
c\left(z_{0}\right)=\left[\frac{\lambda_{c}^{*}}{1+\left(\lambda_{\mathrm{c}}^{*} / 4 \pi\right) F_{\mathrm{c}}\left(z_{0}\right)}\right] c^{*}\left(z_{0}\right) .
$$


Finally, it is to be noticed that the deviations of those $\lambda^{*}$-values, which were determined by [2] for dislocations of different crystallographic types, amount to less than $4 \%$ of the corresponding $\lambda_{\mathrm{c}}^{*}$-values.

\section{References}

[1] Donolato, C., J. Physique Colloq. 44 (1983) C4-289.

[2] Pasemann, L., Blumtritt, H., Gleichmann, R., Phys. Status. Solidi (a) 70 (1982) 197.

[3] Pasemann, L., Ultrumicroscopy 6 (1981) 237.

[4] Donolato, C., Optik 52 (1978) 19.

[5] Donolato, C., private communication.

[6] Pasemann, L., Phys. Stutus Solidi (a) 69 (1982) K199. 